NBER WORKING PAPER SERIES

\title{
IS THE OBESITY EPIDEMIC A PUBLIC HEALTH PROBLEM? A DECADE OF RESEARCH ON THE ECONOMICS OF OBESITY
}

\author{
Tomas Philipson \\ Richard Posner \\ Working Paper 14010 \\ http://www.nber.org/papers/w14010
NATIONAL BUREAU OF ECONOMIC RESEARCH
1050 Massachusetts Avenue
Cambridge, MA 02138

May 2008

We are thankful to Mary Peate for research assistance. The views expressed herein are those of the author(s) and do not necessarily reflect the views of the National Bureau of Economic Research.

NBER working papers are circulated for discussion and comment purposes. They have not been peerreviewed or been subject to the review by the NBER Board of Directors that accompanies official NBER publications.

(C) 2008 by Tomas Philipson and Richard Posner. All rights reserved. Short sections of text, not to exceed two paragraphs, may be quoted without explicit permission provided that full credit, including (C) notice, is given to the source. 
Is the Obesity Epidemic a Public Health Problem? A Decade of Research on the Economics of Obesity Tomas Philipson and Richard Posner

NBER Working Paper No. 14010

May 2008

JEL No. I18

\begin{abstract}
$\underline{\text { ABSTRACT }}$
The world-wide and ongoing rise in obesity has generated enormous popular interest and policy concern in developing countries, where it is rapidly becoming the major public health problem facing such nations. As a consequence, there has been a rapidly growing field of economic analysis of the causes and consequences of this phenomenon. This paper discusses some of the central themes of this decade long research program, aiming at synthesizing the different strands of the literature, and to point to future research that seems particularly productive.
\end{abstract}

Tomas Philipson

Irving B. Harris Graduate School

of Public Policy Studies

The University of Chicago

1155 E 60th Street

Chicago, IL 60637

and NBER

t-philipson@uchicago.edu

Richard Posner

United States Court of Appeals

Richard_Posner@ca7.uscourts.gov 


\section{Section 1: Introduction}

The recent rise in obesity has generated enormous popular interest and policy concern in developing countries, where it is rapidly becoming a major health problem. But obesity (which we define broadly and loosely as weight significantly in excess of what the health-care industry deems normal) is not only a public health issue; it is also an economic problem in several respects. First, it is, in major part at least, a function of two choices that people make: the number of calories to consume and the number to expend; the more the former number exceeds the latter, the more weight a person will gain. Consuming calories comes with costs and benefits, and likewise expending calories through exertion. Second, obesity has changed over time and differs across populations; and, to the extent that it is a product of choice, explaining these changes and differences is a task for economics. The rate of the rise in obesity will also depend on biological factors that vary, within a range, across persons and time, but such factors alone, including genes, cannot explain the rise in obesity, because it has happened much too quickly to be explicable in evolutionary terms. Third, obesity may create social as well as private costs, and, if so, there is a question whether the government should intervene to try to reduce obesity. Fourth, the answer to that question depends, to the economist, on the cost of alternative methods of public intervention and the benefits, in reducing the social costs of obesity, that each method can be expected to produce. A growing scholarly literature in economics and other social sciences addresses the growth in obesity. We shall discuss the positive and normative analysis of obesity found in that literature, but our particular focus is a recent anthology of articles, primarily economic, on obesity (Zoltan Acs and Alan Lyles 2007).

From a positive perspective, the long run growth in obesity is most easily explained by changes in the price of consuming and expending calories. Agricultural innovation has greatly reduced the time and resources required to go from hungry to full. Human beings used to spend most of their time and energy on producing food. The switch from agricultural economies to ones based on manufacturing and later services was made possible by a dramatic gain in agricultural productivity that greatly reduced the cost of consuming calories. At the same time, technological changes in other forms of production, notably the movement from manual labor to automation, simultaneously raised incomes and increased the price of spending calories, as exercise was no longer a byproduct of work, as it had been when work was mainly manual. The gymand jogging revolution resulted from the reallocation of exercise from working time to leisure time. These economic changes explain the cross-sectional and time-series patterns of obesity better than do biological factors, addiction, and cultural changes, none of which alone can explain why Africans are less obese than Americans or why obesity has increased in the near term. 
From a normative perspective, obesity may be a private health problem rather than a public one. The fact that population is overweight in a medical sense does not imply that it is necessarily overweight in a Pareto sense.

\section{Section 2: Positive Aspects of the Growth in Obesity}

Weight is clearly the outcome of diet and exercise, and both these factors are needed to explain long-run weight trends in the United States. During the twentieth century, weights rose even when the total consumption of food did not, presumably due to a fall in spending of calories; the immediate postwar period witnessed substantial growth in weight and declining consumption of calories. This suggests that analysis of obesity must account not only for food consumption, but also for changes in the strenuousness of work and leisure, both at home and in the market, caused by economic development (Darius Lakdawalla, Tomas Philipson and Jayanta Bhattacharya 2005).

The neoclassical theory of obesity (Philipson and Richard Posner 1999; Lakdawalla and Philipson 2002) stresses that technological change provides the best explanation of the time-series data. While food has gotten cheaper through technological change in agriculture, exercise has gotten more expensive, as work (at home and in the market) has become less physically demanding through technologies that at the same time raise productivity and lower calorie spending. The theory also stresses the complementarities of calorie consumption and calorie expenditure. Cheaper food results in more eating, higher weight, and more exercise. Similarly, as the implicit price of exercise rises, there is less exercise, higher average weight, and less food consumption as people substitute toward other forms of weight control. The declining price of food and the rising price of exercise thus have offsetting impacts on food consumption, which is why the twentieth-century data shows periods of both rising and falling food consumption in spite of continual increases in weight and falling food prices.

The neoclassical weight model also yields predictions about the relation between income and weight. Health, or "closeness" to one's preferred "ideal" weight, is likely to be a normal good, which implies a non-monotonic relationship between income and weight. For poor, underweight people, income growth leads to more food consumption and a drive to increase weight, while among well-off, overweight people, income growth might lead to weight loss as people invest resources on striving to attain their ideal weight. Thus in rich countries income raises weight among the poorest groups but lowers it throughout the upper half of the income distribution. In addition, while income has a non-monotonic effect on weight within countries, it has a strong 
positive effect across countries - a greater effect than can be accounted for by aggregation. The impact of technology on weight is essential to interpret this pattern. Across countries, more sedentary but more productive technologies are employed, causing both income and weight to rise.

Behavioral theories of obesity have been proposed (e.g., David Cutler, Edward L. Glaeser, and Jesse M. Shapiro 2003), following the initial work on rational addiction by Gary Becker and Kevin Murphy (1988) and the more recent applications of this model to obesity by John Cawley (1999) and Timothy Richards et al. (2007). They can help us understand why people seek selfcontrol or commitment devices (for example by joining a Weight Watchers group or undergoing bariatric surgery), but commitment issues alone, as initially discussed by Thomas Schelling 1978, do not explain well the crosscountry and time-series evidence on obesity.

Evidence related to the importance of technological change in driving weight change has been developed in several contexts. Lakdawalla and Philipson (2002) provide evidence that the strenuousness of work has very large effects on weight, while Cutler, Glaeser, and Shapiro (2003) emphasize the declining time cost of preparing food, as a result of technological change in food processing. They also note that U.S. consumption of snack foods rose after their prices declined. But since obesity is a worldwide phenomenon, caution must be taken in generalizing from explanations tied to particular circumstances in the United States. Shin-Yi Chou, Michael Grossman, and Henry Saffer (2004) analyze a wide variety of price effects and find that weight seems to rise with: lower relative prices of food at home, lower relative prices of fastfood and full-service restaurants, the wider availability (and hence the lower full price) of such restaurants, lower relative prices of alcohol, and higher relative prices of smoking. ${ }^{1}$ In addition, the percentage of income spent on food has steadily declined since the Great Depression (Judy Putnam 2000). Lakdawalla and Philipson (2002) report that about half the growth in weight since the late 1970 s can be explained by the declining relative price of food. Lakdawalla et al. (2005) report similar findings for food quality, as opposed to quantity: increases in the relative prices of certain types of foods seem to increase the prevalence of deficiencies in nutrients from those foods. For example, when orange juice is more expensive, Vitamin $\mathrm{C}$ deficiency rises, and so on.

The social aspects of obesity may have a multiplier effect on the growth of obesity. When obesity is relatively rare, it is considered abnormal and repulsive, and this negative response helps to keep it in check. As obesity begins to rise, the negative image of obesity becomes less intense because obesity is

\footnotetext{
${ }^{1}$ Cawley et al. (2004) focus more specifically on the effect of smoking on weight: they show that adolescents, particularly females, sometimes initiate smoking as a method of weight control.
} 
now more common (see also Amnon Levy 2002). Hence one cost of obesity declines, and this helps obesity continue to grow. At some point, however, the health effects of obesity become so serious that the reduction in the negative image of obesity is offset by health costs.

Childhood obesity has grown along with adult obesity, and indeed these are positively correlated because technological change in leisure (e.g., computers and television) has raised utility while lowering calorie expenditure. Kids are free to play outside if they wish, but they prefer to play inside, on their computers. Cawley (2006) argues that parental control and bounded rationality are important factors in childhood obesity. (He repeats the argument in his chapter-chapter 3-of the Acs and Lyles volume.) They may be important factors, but that is nothing new, and so cannot explain the growth in childhood obesity. Since children (after infancy) generally eat the same meals as their parents, food-related factors promoting adult obesity will work similarly with children. In another chapter (chapter 5) of the Acs and Lyles volume, Cawley discusses the effect of obesity on income (see also Jeff Biddle andDaniel Hamermesh 1994, 1998; Susan Averett and Sanders Korenman 1996; Charles Baum and William Ford 2004; Cawley 2004; Stephen Morris 2006). To isolate that effect, he compares the wages of siblings of different weight. Surprisingly, he finds that the only effect is in reducing the wages of obese relative to normal white women. ${ }^{2}$

The rise in obesity in other developed countries has lagged the rise in the United States, and this leads Audrestsch and DiOrio, in chapter 2 of the Acs and Lyles volume, to argue that obesity is a negative outgrowth of today's American culture, with its emphasis on fast food and the rise of light service industries, and is bundled with other American practices and transferred to other countries through globalization. A more straightforward explanation, and one more consistent with economic analysis, is that, rather than imitating the United States, countries at a similar stage of development exhibit similar behaviors in their population because the same causal factors, such as rising income and automation, are at work.

Regarding the future of obesity, Acs et al., in chapter 8 of the Acs and Lyles volume, predict that by 2016 half the U.S. population will be obese, compared to about a third at present. There is too much uncertainty about the demand for and supply of the factors that influence obesity to justify placing much weight on such a prediction, but the income or education effect on health will clearly be an important offsetting force to the further impact of technological change. The future of obesity depends on which of two effects on obesity that

\footnotetext{
${ }^{2}$ However, Bhattacharya and Kate Bundorf (2005) estimate that most of this wage differential can be explained by the higher health care premiums employers must pay for obese workers.
} 
stem from income growth dominate: the more sedentary way the higher income is generated or the larger demand for health it induces.

\section{Section 3: Normative Aspects of the Growth in Obesity}

Naturally, when obesity is regarded as a public health issue government intervention to control is recommended as soon as a substantial percentage of the population weighs more than is optimal for maximizing health. From an economic standpoint, the proper maximand is of course not health but utility, in which good health is only one argument. Rational persons constantly trade off health for competing goods, such as pleasure, income, time, and alternative consumption possibilities. Intervention that considers such tradeoffs unworthy of consideration is paternalistic. This is recognized in such areas as highway safety-no one proposes to shut down highways in order to reduce traffic deaths, or to force automobile manufacturers to equip their cars with engines that limit top speed to 25 miles per hour-but the principle that legitimizes trade-offs involving life and health is equally applicable to obesity. The point is not that governmental efforts to control obesity should be ruled out of bounds a priori, but that all relevant costs and benefits of such efforts should be considered.

This is particularly important in analyzing the claim that public intervention to control obesity is justified because of the higher average medical expenses of the obese on public health insurance, such as Medicare and Medicaid ${ }^{3}$. We are skeptical that such fiscal externalities are the true underlying concern of the public health community. This is because other fiscal effects, such as higher mortality rates of obese individuals (Lawrence Garfinkel 1986) which reduce Social Security spending, are not considered (e.g.,Roland Sturm 2002; Joy, Goldman and Pradham 2006). Elsie Pamuk et al. 1992, 1993 find that weight loss for individuals with healthy BMIs and for women with high BMIs is associated with higher mortality rates. An exception is McCormick and Stone (2007) who argue that the medical expenses associated with obesity have been exaggerated because the cost savings resulting from the tendency of obese people to die earlier. However, standard analysis (Fred Kuchler and Nicole Ballenger 2002; Eric Finkelstein et al. 2004, 2005; and Ostbye et al. 2007) focuses on health care alone.

Nor are insurance externalities a good argument for public intervention to reduce obesity. Rather they are an argument for experience-rating health insurance, so that groups with above-average expected medical expenses pay higher insurance premiums (Bhattacharya and Neeraj Sood 2005). There is

\footnotetext{
${ }^{3}$ In the spirit of the early work by Emmett Keeler et al. (1989), Grossman and Rashad (2004) have argued that obesity externalities are created by public health insurance pools.
} 
no reason to single out obesity as a basis for higher insurance costs, since there are other, equally or more, risky "life style" choices that increase expected medical costs.

It is unclear whether obesity would create externalities if insurance were allowed to adjust. A more serious problem may be a combination of consumer ignorance with seller exploitation (discussed by Gould and Sussan in chapter 6 of Ace and Lyles) based on people's addictive tendencies having biological roots; in the ancestral environment to which human beings were biologically adapted, a taste for high-caloric foods had great survival value.

\section{Section 4: Specific Actual and Proposed Interventions}

The principal public interventions, actual or proposed, thus far are education, taxation, fast-food regulation, and a little of everything on the model of the campaign against cigarette smoking.

\subsection{Education}

Education is the most frequently proposed and implemented public intervention to control obesity. It comes in several forms, including requirements for furnishing nutritional information on labels for food products, publicly financed advertising of the health consequences of obesity (similar to publicly financed advertising against smoking), nutrition- or exercise education, and general education. The motivation for such interventions is the observation, emphasized by Henderson in chapter 4 of the Acs and Lyles volume, that obesity varies across socioeconomic, racial, and cultural groups (and even geographically), even though food is cheaper and work and leisure are more sedentary for everyone. But deficiencies in education and information cannot be the key to explaining the growth of obesity, since people have become much better informed about characteristics of food, including calories, as a result of food labels, diet advertising, and publicity about obesity. Incentives created by technological change have more than offset the increased understanding of caloric intake and expenditure. Thus, the effectiveness of labeling in combating obesity has not been confirmed in the empirical literature (See Lorna Aldrich 1999; Kim et al. 2001; Jayachandran Variyam and Cawley 2006; Maria Loureiro et al. 2006).

Still, particular subgroups in the population may be more ignorant than others about the health effects of obesity and about the foods that conduce to obesity. Of course there may be other factors; the feedback effect that we noted earlier may be especially important among groups, such as black and Hispanic women, where obesity is so common as to be normal, reducing social 
pressures to be thin. However, Henderson's analysis of three educational weight-loss programs targeted on vulnerable groups presents no statistical evidence that such programs are effective.

In chapter 9 of Acs and Lyles, Parke Wilde discusses the ineffectuality of federal efforts to educate the public about a healthy diet. The government issues dietary guidelines that if followed would reduce obesity, but at the same time, through its commodity check-off program, it mandates promotional advertising for beef, pork, and other high-caloric foods. The result, Wilde argues, is to increase the demand for fad diets, which promise quick results enabling consumers to continue or soon resume eating their favorite foods but do not deliver.

Probably most of the obese population understands the mechanisms by which weight is gained and lost, and so additional nutritional education would have only a very limited effect. If we randomized our existing government programs for educating people about overweight and then measured weight five years later, it is unlikely that those who received the nutrition education would be thinner. (Kamhon Kan and Wei-Der Tsai 2004 suggest otherwise)

More promising are programs of general education focused on increasing years of schooling for vulnerable populations (e.g., Variyam and Blaylock 1998). The problem is not that disadvantaged persons cannot read labels and are unaware that obesity is bad for their health, but that uneducated persons have less of an incentive to invest in their health because their longevity and their utility from living are below average. ${ }^{4}$

\subsection{Taxation}

An excise tax on food would reduce consumption, though it would be regressive. A better form of obesity tax would be a nonlinear tax-a tax on overconsumption of food-rather than a flat tax on all sales of food. But such a tax would be extremely difficult to enforce; it would be the equivalent of taxing fat people. Elston et al., in chapter 10 of Acs and Lyles, analyze four linear tax responses to obesity - a tax on all foods, a tax proportional to particular ingredients (such as sugar or butter), a tax applied to categories of foods, and a value-added tax on food producers. The last, which is the one they favor, would be proportioned to the difference between the price of the raw inputs and the selling price of the finished product, and thus would penalize heavily processed products. This is a feasible linear-tax response to obesity, although its effects would probably be quite limited. In principle the ingredient tax is attractive, but Elston's chapter (pp. 184-185) presents a number of compli-

\footnotetext{
${ }^{4}$ For a discussion on weight as a signaling mechanism to potential mates, see Avner Offer 2001.
} 
cating factors (see also Kuchler et al. 2005). Probably any feasible tax response to obesity would cost more to enforce than it would be worth in reducing the social costs of obesity.

\subsection{Fast Food Regulations}

The shift of producing and preparing food from the home to the market (due to the increase in the market value of women's time), in particular to fastfood preparation and carry-out, is often believed to be an important factor in the rise of obesity, though data are sparse. Chou, Grossman, and Inas Rashad (2006) find a strong correlation between obesity and fast-food establishments across regions. This strong correlation is puzzling, given that the vast majority of meals are still home-produced. ${ }^{5}$ )

Acs et al., in chapter 8 of the Acs and Lyles volume, proposed restricting access to vending machines and the location of fast-food restaurants. These would be costly measures of uncertain efficacy, given substitution possibilities. Regulation of advertising may affect obesity growth more substantially. The food industry is the second largest advertiser in the United States (after the automotive industry) (Mary Story and Simone French 2004). In addition, 11 percent of food advertising geared to children is advertising for fast food and only 2 percent for foods low in sugar, fat, and salt, and almost no ads are directed at children for fruit or vegetables (Margot Wooten 2003).

\subsection{The Tobacco Precedent}

Levy and Oblack, in chapter 11 of Acs and Lyles, point out that federal, state, and local government have attempted with considerable success to curb tobacco consumption through a combination of mandatory warnings in and other restrictions on labeling and advertising, media campaigns, stiff taxes, highly publicized lawsuits, and location restrictions that have culminated in the prohibition of smoking in most public places. Very little, in contrast, has been done to limit obesity, perhaps rightly so if obesity has less external costs than smoking. In any event, the tobacco model has only limited applicability to obesity. It is relatively easy not to begin smoking, so that over time campaigns designed to arouse public awareness of the dangers of smoking, and to increase the expense of the habit as well as creating a nonmonetary inconvenience cost resulting from the location restrictions, reduce the number of smokers even if no current smokers are able to break their habit. Everyone

\footnotetext{
${ }^{5}$ Joanne Guthrie et al. (2002), on the basis of 1996 data, estimated that only 17 percent of total calories consumed by men aged 18 to 39, and 13 percent of the total calories consumed by women in that age group came from fast-food establishments.
} 
has to begin eating, however, and having begun one is highly susceptible to becoming obese as a result of biological predisposition, poor information, and the asymmetry of gaining and losing weight (gaining easy, losing hard). Stiff taxes on food, in contrast to stiff taxes on cigarettes, would be intolerable for persons of modest means, and ingredient, nonlinear, and other superior forms of taxing calories are unlikely to be feasible and effective. In chapter 12 of Acs and Lyles, Anderson argues that class actions against the fast-food industry can be effective in reining in obesity, but these actions are likely to fail for the same reason that most suits by smokers against cigarette companies have failed: juries see the illness resulting from voluntary consumption of dangerous products to be self-inflicted and hence not compensable. 


\section{References}

Acs, Zoltan J., and Alan Lyles, Obesity, Business and Public Policy (Edward Elgar Publishing Ltd. 2007).

Aldrich, Lorna, U.S. Dept. of Agriculture, Economic Research Service, Consumer Use of Information - Implications for Food Policy (June 1999).

Averett, Susan, and Sanders Korenman. 1996. "The Economic Reality of the Beauty Myth." Journal of Human Resources,31(2): 304-30.

Baum, Charles L., and William F. Ford 2004. "The Wage Effects of Obesity: A Longitudinal Study." Health Economics, 13(9): 885-99.

Becker, Gary S., and Kevin M. Murphy. 1988. "A Theory of Rational Addiction." Journal of Political Economy, 96(4): 675-700.

Bhattacharya, Jayanta and Bundorf, M. Kate, "The Incidence of the Healthcare Costs of Obesity." (May 2005). NBER Working Paper Series, No. W11303.

Bhattacharya, Jayanta and Neeraj Sood. 2005. Health Insurance and the Obesity Externality, National Bureau of Economic Research, Inc, NBER Working Papers No. W11529.

Hamermesh, Daniel S., and James E. Biddle. 1994. "Beauty and the Labor Market." American Economic Review, 84(5): 1174-94.

Hamermesh, Daniel S., and James E. Biddle. 1998. "Beauty, Productivity, and Discrimination: Lawyer's Looks and Lucre." Journal of Labor Economics, 16(1): 172-201.

Cawley, John. 2006. "Markets and Childhood Obesity Policy." The Future of Children, special issue on Childhood Overweight and Obesity, 16(1): 69-88.

Cawley, John. 1999. "Obesity and Addiction." Ph.D. Dissertation, University of Chicago, Department of Economics. Chicago, IL.

Cawley, John. 2004. "Impact of Obesity on Wages." Journal of Human Resources, 39(2): 451-74.

Cawley, John, Sarah Markowitz, and John Tauras 2004. "Lighting Up and Slimming Down: The Effects of Body Weight and Cigarette Prices on Adolescent Smoking Initiation." Journal of Health Economics, 23(2): 293-311.

Chou, Shin-Yi, Michael Grossman, and Inas Rashad. Fast-Food Restaurant Advertising on Television and Its Influence on Childhood Obesity, National Bureau of Economic Research, Inc, Working Paper 11879 (Dec. 2006).

Chou, Shin-Yi, Michael Grossman, and Henry Saffer. 2004. "An economic analysis of adult obesity: results from the Behavioral Risk Factor Surveillance System." Journal of Health Economics, 23(3): 565-87.

Cutler, David M., Edward L. Glaeser, and Jesse M. Shapiro. 2003. "Why Have Americans Become More Obese?" Journal of Economic Perspectives, 17(3): 93-118. 
Finkelstein, Eric A., Ian C. Fiebelkorn, and Guijing Wang. 2004. "State-level estimates of annual medical expenditures attributable to obesity." Obesity Research,12(1): 18-24.

Finkelstein, Eric A., Christopher Ruhm, Katherine Kosa. 2005. "Economic Causes and Consequences of Obesity." Annual Review of Public Health, 26:239-257.

Flegal, K. M., et al. 1998. "Overweight and obesity in the United States: prevalence and trends, 1960-1994." International Journal of Obesity and Related Metabolic Disorders, 22(1): 39-47.

Flegal, K. M., et al. 2002. "Prevalence and Trends in Obesity Among US Adults, 1999-2000." Journal of the American Medical Association, 288(14): 1723-1727.

Garfinkel, Lawrence. 1986. "Overweight and Mortality." Cancer, 58(8 Suppl): 1826-9.

Grossman, Michael, and Inas Rashad. 2004. "The Economics of Obesity." Public Interest, (156): 104-112.

Guthrie, Joanne, Biing-Hwan Lin,and Elizabeth Frazao. 2002. "Role of Food Prepared Away from Home in the American Diet, 1977-78 versus 199496: Changes and Consequences." Journal of Nutrition Education Behavior, 34:140-150.

Joy, A.B., Goldman, G., and Pradhan, V. (2006) "Cost-benefit analysis conducted for nutrition education in California." California Agriculture, 60(4):185.

Kan, Kamhon, and Wei-Der Tsai. 2004. "Obesity and Risk Knowledge." Journal of Health Economics, 23(5): 907-34.

Keeler, Emmett, et al. 1989. "The External Costs of a Sedentary Life-style." American Journal of Public Health, 79(8): 975-81.

Kim, S.Y., R. Nayga und O. Capps. 2001."Food Label Use, Self-Selectivity, and. Diet Quality." Journal of Consumer Affairs, 35(2):346-363.

Kuchler Fred, and Nicole Ballenger 2002. "Societal costs of obesity: how can we assess when federal interventions will pay?" FoodReview, 25:33-37.

Kuchler, Fred, et al. 2005. "Obesity Policy and the Law of Unintended Consequences." Amber Waves, 3(3):26-33.

Lakdawalla, Darius, Tomas Philipson, and Jayanta Bhattacharya. 2005. "Welfare-Enhancing Technological Change and the Growth of Obesity." American Economic Review, 95(2): 253-257.

Lakdawalla, Darius N., and Tomas J. Philipson. 2002. "Technological Change and the Growth of Obesity." National Bureau of Economic Research Working Paper 8946. Cambridge, MA: National Bureau of Economic Research.

Levy, Amnon. 2002. "Rational Eating: Can It Lead to Overweightness or Underweightness?" Journal of Health Economics, 21(5): 887-99. 
Loureiro, Maria,Azucena Gracia, and Rodolfo M. Nayga. 2006. "Do Consumers Value Nutritional Labels?" European Review of Agricultural Economics 33(2): 249-268.

McCormick, B., I. Stone, Corporate Analytical Team (2007). "Economic costs of obesity and the case for government intervention." Obesity Reviews, 8(1): 161-164.

Morris, Stephen. 2006. "Body Mass Index and Occupational Attainment." Journal of Health Economics 25(2): 347-364.

Offer, Avner. 2001. "Body weight and self control in the United States and Britain since the 1950s." Soc Hist Med, 14:79-106.

Ostbye T, Dement JM, Krause KM 2007. "Obesity and workers' compensation: Results From the Duke Health and Safety Surveillance System." Arch Intern Med, 167:766-773.

Pamuk, Elsie R., et al. 1992. "Weight loss and mortality in a national cohort of adults, 1971-1987." Am J Epidemiol, 136(6): 686-97.

Pamuk, Elsie R., et al. 1993. "Weight loss and subsequent death in a cohort of U.S. adults." Ann Intern Med, 119(7 Pt 2): 744-8.

Philipson, Tomas J., and Richard A. Posner 1999. "The Long-Run Growth in Obesity as a Function of Technological Change." National Bureau of Economic Research Working Paper 7423. Cambridge, MA: National Bureau of Economic Research.

Putnam, Judy J. 2000. "Major Trends in US Food Supply: 1909-99." Food Review, 23(1): 8-15.

Richards, Timothy J., Patterson, Paul M. and Tegene, Abebayehu 2007. "Obesity and Nutrient Consumption: A Rational Addiction?" Contemporary Economic Policy 25(3): 309-324.

Schelling, Thomas. C. 1978. "Egonomics, or the Art of Self-Management." American Economic Review, 68(2): 290-94.

Story, Mary, and Simone French. "Food Advertising and Marketing Directed at Children and Adolescents in the US." 1-3 International Journal of Behavioral Nutrition and Physical Activity, 1, 2 (2004).

Sturm, Roland. (2002). "The effects of obesity, smoking, and drinking on medical problems and costs. Obesity outranks both smoking and drinking in its deleterious effects on health and health costs." Health Affairs, 21(2): 245-53.

Variyam, Jayachandran N. 2005. "The Price is Right: Economics and the Rise in Obesity." Amber Waves 3(1):20-27.

Variyam Jayachandran N., and Russel Blaylock. 1998. "Unlocking the mystery between nutrition knowledge and diet quality." Food Review, 21:21-28.

Variyam, Jayachandran N., and John Cawley. 2006. "Nutrition Labels and Obesity." National Bureau of Economic Research Working Paper 11956, National Bureau of Economic Research, Inc., Cambridge, MA. 
Wooten, Margo G. 2003. "Pestering Parents: How Food Companies Market Obesity to Children." Social Policy Report, 20(2): 3-17. 